\title{
Authors Alliance
}

\section{A force to promote authorship for public good}

A uthors create for different purposes. Those who create to be read, to be seen, and to be heard and would like to share their knowledge and creativity freely via the Internet may face barriers that prevent broad public access to their works. For instance, their works may be un-digitized and subject to copyright restrictions. Authors who are eager to share new works may feel torn between publication outlets that maximize public access and others that restrict access but provide important value in terms of peer review, prestige, or monetary reward. Authors may also struggle to understand how to navigate fair use and the rights clearance process in order to lawfully build on existing works.

There is now a nonprofit organization that aims to lend a helping hand to authors who encounter any of the above-mentioned issues. Established in May 2014, the Authors Alliance promotes authorship for the public good by assisting authors who wish to disseminate knowledge and products of creativity as widely as possible. ${ }^{1}$ The Alliance embraces the unprecedented potential of digital networks and represents authors who want to harness this potential to share their creations broadly in order to serve the public good. The Alliance provides authors with information and tools to better understand and manage key legal, technological, and institutional aspects of authorship in the digital age.

The Authors Alliance is also a voice for authors in discussions about public and institutional policies that might promote or inhibit the broad dissemination they seek. The Alliance's Board of Directors is comprised of four University of CaliforniaBerkeley professors, including the University Librarian. Additionally, the Alliance is supported by an Advisory Board whose members include librarians, professional writers, publishers, and academics from a variety of disciplines. ${ }^{2}$

\section{Four issues for authors}

The Authors Alliance focuses its efforts on four strategic issues. First, it helps authors understand and manage the rights necessary to make their works broadly available now and in the future. The Alliance has created an educational FAQ that clarifies such concepts

Michael Wolfe is executive director of Authors Alliance, email: mike@authorsalliance.org, Adrian K. Ho is director of digital scholarship at University of Kentucky Libraries, email: adrian.ho@uky.edu

Contact series editors Zach Coble, digital scholarship specialist at New York University, and Adrian Ho, director of digital scholarship at the University of Kentucky Libraries, atcrlnscholcomm@gmail.com with article ideas

○ 2015 Michael Wolfe and Adrian K. Ho 
as authorship, ownership, and work made for hire under U.S. copyright law. ${ }^{3}$ It also explains how an author can rely on contractual reversion rights, statutory termination of transfer rights, or fair use to tackle complications that might arise when the author is no longer the owner of copyright in a work he or she created. Moreover, it offers examples of how authors can manage their copyright in order to facilitate wide dissemination and reuse of their works.

The Authors Alliance has also invited Michael Carroll, professor at American University, to shed light on how author addenda can modify publishing contracts in such a way that authors will keep the rights that are instrumental in boosting the availability of their works. ${ }^{4}$ A founding member of the Alliance, Carroll notes that publishers have different reactions to authors' submission of an addendum, but the use of it has prompted publishers to sometimes change their copyright agreements to make them more reasonable. He adds that authors should step up and request the retention of certain rights when publishing their journal articles. Publishers will not forsake the opportunity to publish an accepted article simply because the author asks for keeping some rights.

Another issue the Authors Alliance targets is authorship law and policy. The Alliance provides education and advocacy for sound policies that help authors create their works, make them accessible to the public, and ensure their preservation. Such policies include laws and regulations as well as institutional policies at universities, funding organizations, etc.

The Alliance advocates a "Next Great Copyright Act" that will appropriately align the interests of individual creators with those of the public. As the first step toward this goal, the Alliance launched with the announcement of a set of Principles and Proposals for Copyright Reform. ${ }^{5}$ These are the four principles laid down in the document:

1. Further empower authors to disseminate their works. Public-minded authors need a legal toolkit to enable us to take advantage of the unprecedented opportunities presented by global digital networks so that a new and globally expanding generation of readers, viewers, and listeners can find and enjoy our works.

\section{Improve information flows about} copyright ownership. The copyright system works best when we authors, as well as the public, can identify and locate copyright owners. Accurate ownership records facilitate securing permission to use works and help clearly establish how long copyright lasts for any given work. In doing so, they prevent works from becoming "orphans," that is, works still protected by copyright whose owners cannot be found. Because we worry about oblivion for works that are locked into copyrights for which no one can find the key, the law needs to provide better incentives for rights holders to provide accurate information on copyright ownership. Transparency will benefit authors, readers, and intermediaries alike.

\section{Affirm the vitality of limits on copyright} that enable authors to do their work and reach more audiences. Authors routinely rely on copyright's limitations as well as its rights. By making knowledge and creative works available to future scholars and creators, fair use and other limitations on copyright are vital to our work as authors and to the public's ability to locate, preserve, and use our works now and for generations to come. Copyright law should continue to keep the basic building blocks of authorship unshackled and free for all to use. We need a copyright law that favors dissemination and combats obscurity by explicitly making room for technologies and intermediaries that preserve, archive, and index our works so that they might survive us and reach new audiences. We need a copyright law that does not needlessly restrict access to works whose owners can no longer be found. Many of these limitations exist in the law as it stands today, but they need to be 
clarified, protected, and, where appropriate, extended.

\section{Ensure that copyright remedies and} enforcement mechanisms protect authors' interests. Copyright law should provide reasonable remedies for infringement of authors' rights, but the law should calibrate these remedies so they do not discourage or silence the kinds of creativity the law was designed to incentivize.

Each principle is supported by a variety of concrete proposals that would help see it realized. Taken together, these would help protect and extend the public domain, combat the orphan works problem, and strengthen author's abilities to retain, regain, and receive credit for their creative works.

In addition to the Principles and Proposals for Copyright Reform, the Alliance has made available an educational FAQ about fair use. ${ }^{6}$ It discusses concisely what fair use is and what constitutes "transformative" and "non-transformative" uses. There are also explanations about the consideration of best practices and case law in the process of assessing whether a use is fair.

The third issue the Authors Alliance addresses is about reaching audiences. The Alliance works with authors to identify online platforms, tools, techniques, and partners that enable them to broaden the communication with their audiences. The Advisory Board includes experts in publishing, librarianship, new media, and digital dissemination. They play a significant role in finding possible solutions, but the founding members also bring valuable insights in this regard.

For example, Lydia Loren, professor at Lewis and Clark Law School and founding member of the Alliance, partnered with a colleague to launch Semaphore Press in 2008 to pursue an alternative business model of publishing casebooks for law school classes. ${ }^{7}$ Semaphore Press eliminates such traditional publishing costs as printing, marketing, and product delivery. By focusing on selling its books online, it is able to price each book at $\$ 30$ instead of the usual price of $\$ 200$.

To ensure that students can gain access to their class readings, Semaphore Press even offers an option for students to pay whatever amount they choose. Additionally, it handles the author's remuneration and the copyright to the books in a nontraditional manner. It pays $50 \%$ of the profits as the royalty and seeks a five-year license from the author rather than a wholesale copyright transfer for publishing the work. The licensing will be revisited when the five-year term expires. In sum, Loren encourages authors and publishers to experiment with different publishing business models to produce affordable educational materials students need.

Another founding member of the Authors Alliance, Don Herzog, professor at the University of Michigan, has also taken advantage of the Internet to disseminate his work. While he was finishing his book, he collaborated with the campus library to deposit a Creative Commons-licensed version in the institutional repository for free access. ${ }^{8}$ Despite the unfettered online availability, a university press decided to publish the book as a print monograph and even agreed to make the published version freely accessible in the same institutional repository.

When looking back, Herzog remarks, "My bet is that scholarly publication is heading for free online distribution, faster than you might think. A good thing, too. Who needs derisory royalties when you can have readers?"

Meanwhile, Christopher Sprigman, professor at New York University and a founding member of the Alliance, has found another way to increase the readership of his work. With the assistance of a literary agent, he and his colleague coauthored a "crossover" book in order to negotiate for a lower sale price and to render it accessible to more readers. ${ }^{10}$ As an author who writes to be read, he comments that the experience was worthwhile and did not compromise the academic nature that underlies the book. To complement these inspiring examples of 
furthering reach to the public, the Authors Alliance has compiled an FAQ to introduce authors to the concept and practices of open access. ${ }^{11}$

The fourth issue examined by the Authors Alliance centers on authorial reputation and integrity. The Alliance works to ensure that authors can make their contributions to knowledge and culture widely available without sacrificing their interests in reputation and integrity. A starting point is this suggestion in the Principles and Proposals for Copyright Reform: ${ }^{12}$

The law should recognize the right of authors to be acknowledged as creators of our works. This is especially important for those of us who create in order to contribute to knowledge and culture. Attribution serves not only our interests as authors, but also the reading public's interest in knowing whose works they are consuming and society's interest in an accurate record of the intellectual heritage of humankind.

Authorial reputation and integrity are connected to peer review and promotion in academia. These processes are critical to the research and academic enterprises and may need to adapt in the digital age. The Alliance will be tracking news in this area, creating educational materials, and developing best practices and policy positions.

In conclusion, the Authors Alliance provides resources and guidance to help creators of all kinds better understand and leverage their rights. It aims to demystify the contracts, copyright law, institutional policies, and jargon that stand between authors and their audiences. It promotes policies that would make creative works accessible, discoverable, and properly attributed so as to reflect their authors' contributions to knowledge and culture.

While the Alliance approaches its core issues from the creator's perspective, it considers academic libraries to be essential allies in the process of educating authors and transforming the scholarly communication landscape. By preserving our works and helping our audiences find them, libraries are uniquely positioned to bolster authors' vital interest in being read. The Authors Alliance looks forward to working with libraries and librarians to advance its mission, and encourage all creators who share this mission to become members.

\section{Notes}

1. Authors Alliance: www.authorsalliance. org/.

2. Authors Alliance's Board of Directors and Advisory Board: www.authorsalliance. org/about/.

3. FAQ: Authorship and Ownership in U.S. Copyright Law: www.authorsalliance. org/2014/05/20/authorship-and-ownership -faq/.

4. Michael Carroll on Author Addenda: www.authorsalliance.org/2014/11/14 /michael-carroll-on-author-addenda/.

5. Principles and Proposals for Copyright Reform: www.authorsalliance.org/principles -and-proposals-for-copyright-reform/.

6. Fair Use FAQ: http://www.authorsalliance.org/2014/05/15/fair-use-faq/.

7. Lydia Loren on Semaphore Press: www. authorsalliance.org/2014/11/14/lydia-loren -on-semaphore-press/.

8. U-M's Open Access Project Allows Greater Coverage for Books: https://www. youtube.com/watch?v=CeN4sydIviE.

9. Publishing for Readers: www.publishing. umich.edu/2013/08/01/guest-post-publishing -for-readers/.

10. Christopher Sprigman on Pricing to Be Read: www.authorsalliance.org/2014/11/14 /christopher-sprigman-on-pricing-to-be -read/.

11. Open Access FAQ: www.authorsalliance. org/2014/10/16/open-accessfaq/.

12. Recognize our interests in being attributed as authors of our works: www. authorsalliance.org/principles-and-proposals -for-copyright-reform/principle-1/. 